\title{
HYPOTHESIS
}

\section{Rheumatoid arthritis: A synovial disease?}

\author{
Katsuyuki Fujii, Michiko Tsuji, Mitsuko Tajima
}

\begin{abstract}
Hypothesis
Although rheumatoid arthritis (RA) is believed to be primarily an inflammatory disease of synovium, there is a good possibility that the initiation of the rheumatoid process is triggered by the autoimmune reaction involving type II collagen in the articular cartilage as a consequence of an unknown aetiological agent. Synovitis and other extra-articular features may be induced secondary to the immune complex formation in the subchondral area.

Extensive scientific data on the immune nature of RA have been accumulated. ${ }^{1}$ According to this, RA is considered to be an autoimmune disease that is presently incurable. Although its aetiology remains unknown, most investigators believe that RA is primarily an inflammatory disease of synovial membrane of the joints. However, here we show evidence that RA primarily involves articular cartilage and subchondral bone, not the synovium; this new direction of research may allow for the development of a specific treatment for the disease.
\end{abstract}

It is generally accepted that the initial events in the development of articular damage is the proliferation of synovial cells together with inflammation and vascular neoformation in the stroma of synovial tissue. ${ }^{2}$ As the disease progresses, the proliferating synovial tissue extends over the articular cartilage and erodes from the joint surface down to the subchondral bone. Eventually, small and large joints of the patient are destroyed, deformed and ankylosed.

Recently, we have focused on the following clinical facts that raise an important question: Is RA really a synovial disease? Firstly, although administration of non-steroidal antiinflammatory drugs, anti-rheumatic medicines and corticosteroids is recognised as a fundamental conservative treatment for RA, these cannot completely suppress the synovitis of affected joints. Even after surgical synovectomy, the removal of inflammatory synovial tissue, most cases develop varying degrees of recurrent synovitis with time, and the progression in joint deterioration and deformity cannot be prevented. ${ }^{3-5}$ Secondly, synovitis progression tends to gradually decrease when articular cartilage and bone are severely destroyed in the advanced stages. ${ }^{6}$ Thirdly, active synovitis remarkably diminish after excision of articular cartilage and subchondral bone during prosthetic joint replacement even if the hypertrophied and inflamed synovium remains unremoved. ${ }^{78}$ These findings indicate that synovitis is rather a secondary event caused by a preceding lesion in the articular cartilage and subchondral bone. This notion coincides with our previous observation that anti-type II collagen IgG antibody appears in high incidence during the early phase of RA. ${ }^{9-11}$ The major antigenic determinants that are recognised by RA sera were found to reside in the region represented by cyanogen bromide(C$\mathrm{NBr})$ peptide -11 and $8(\mathrm{CB}-11, \mathrm{CB}-8)$ of human type II collagen molecule. ${ }^{10}{ }^{11}$ Anti-type II collagen antibody was all negative in sera from patients with gout, osteoarthritis (OA) and non-arthritic diseases. ${ }^{9-11}$

To impart an approach for understanding the pathogenesis of RA, we have performed histological and immunohistochemical studies on the arthritic joints (13 knees and 8 hips) of RA patients (21 women, age 27-68 years, mean 58). Articular cartilage and adjacent subchondral bone samples obtained from RA patients during surgery (synovectomy or prosthetic joint replacement) were macroscopically normal, apart from the bare area, and not invaded by synovial pannus. All of the joints demonstrated different degrees of synovial inflammation. Human osteoarthritic and rheumatoid arthritic articular cartilages were examined for type II collagen degradation using antibodies against $\mathrm{CNBr}$ derived peptides of type II collagen. Although histologically, the surface of this cartilage appears smooth and undamaged, immunohistochemical analysis showed less staining for type II collagen and intense staining for $\mathrm{CNBr}$ derived peptides of type II collagen in the deep zone matrix than anywhere else (fig 1). In contrast, the deep zone of articular cartilage from OA patients (10 women, age $42-72$ years, mean 65 ) was stained with antibody against type II collagen. Similar degradation pattern of cartilage matrix in RA was previously shown by Dodge et al. ${ }^{12} \mathrm{~A}$ wholly different mechanism may be the basis of joint destruction in RA and OA. Type II collagen breakdown peptides in the deep zone of rheumatoid arthritic cartilage may become epitopes as we previously pointed out. ${ }^{10}{ }^{11}$ The most striking finding was that there is a considerable formation of islands that invade into the deep zone of articular cartilage through the calcified cartilage from below, where the subchondral bone is located (fig 2). This pattern was observed in 16 of $21(76 \%)$ 

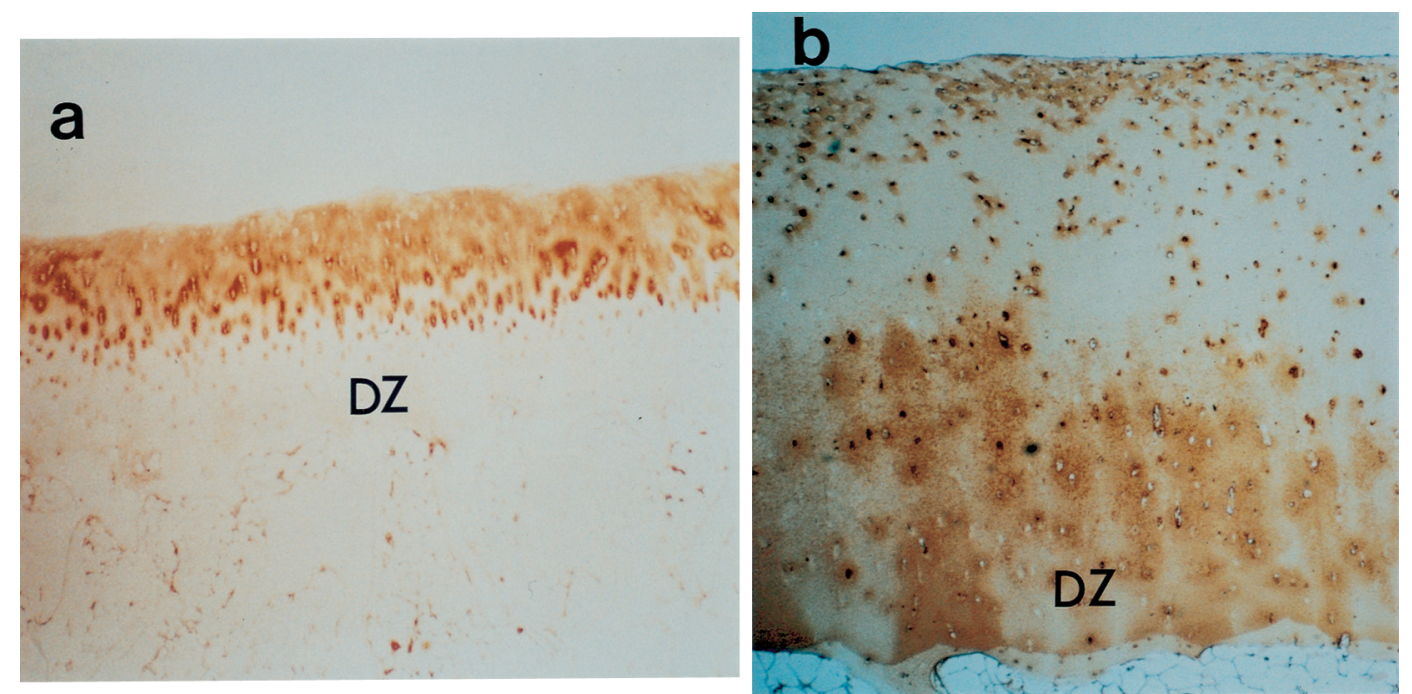

Figure 1 Immunohistochemical identification of type II collagen degradation in rheumatoid articular cartilage. Tibial plateau articular cartilage (woman 52 years) taken apart from joint margins were fixed for six hours at $4^{\circ} \mathrm{C}$ in $2 \%$ paraformaldehyde containing $0.075 \mathrm{M}$ lysine and $0.01 \mathrm{M}$ sodium periodate solution, and washed at $4^{\circ} \mathrm{C}$ with $0.01 \mathrm{M}$ phosphate buffer saline (PBS, pH 7.2) containing glycerol, as previously described by McLean and Nakano. ${ }^{19}$ Then they were decalcified with EDTA-glycerol solution at $-5^{\circ} \mathrm{C}$. The samples were embedded in paraffin wax, and

immunohistochemical analysis was assessed on the sections using the avidin-biotin-peroxidase complex $(A B C)$

immunoperoxidase..$^{20}$ The cartilage sections were stained with monoclonal antibody against human type II collagen (a) and rat polyclonal antibody against CNBr derived peptides of type II collagen (b). Less staining for type II collagen and intense staining for $\mathrm{CNBr}$ derived peptides of type II collagen in the deep zone (DZ) matrix are observed. ((a) Original magnification $\times 6.6$, (b) original magnification $\times 13.2$ ).

samples. These islands are not in contact with the articular margins and contain a significant amount of TRAP positive multinucleated cells. Inflammation was also confirmed in the underlying subchondral bone, and CD68 posi- tive mononuclear cells, MT-1 positive cells, and HLA-DR positive cells were detected. The presence of T cells (MT-1 positive cells) may be crucial for anti-type II collagen IgG antibody production in this region. Pathologi-

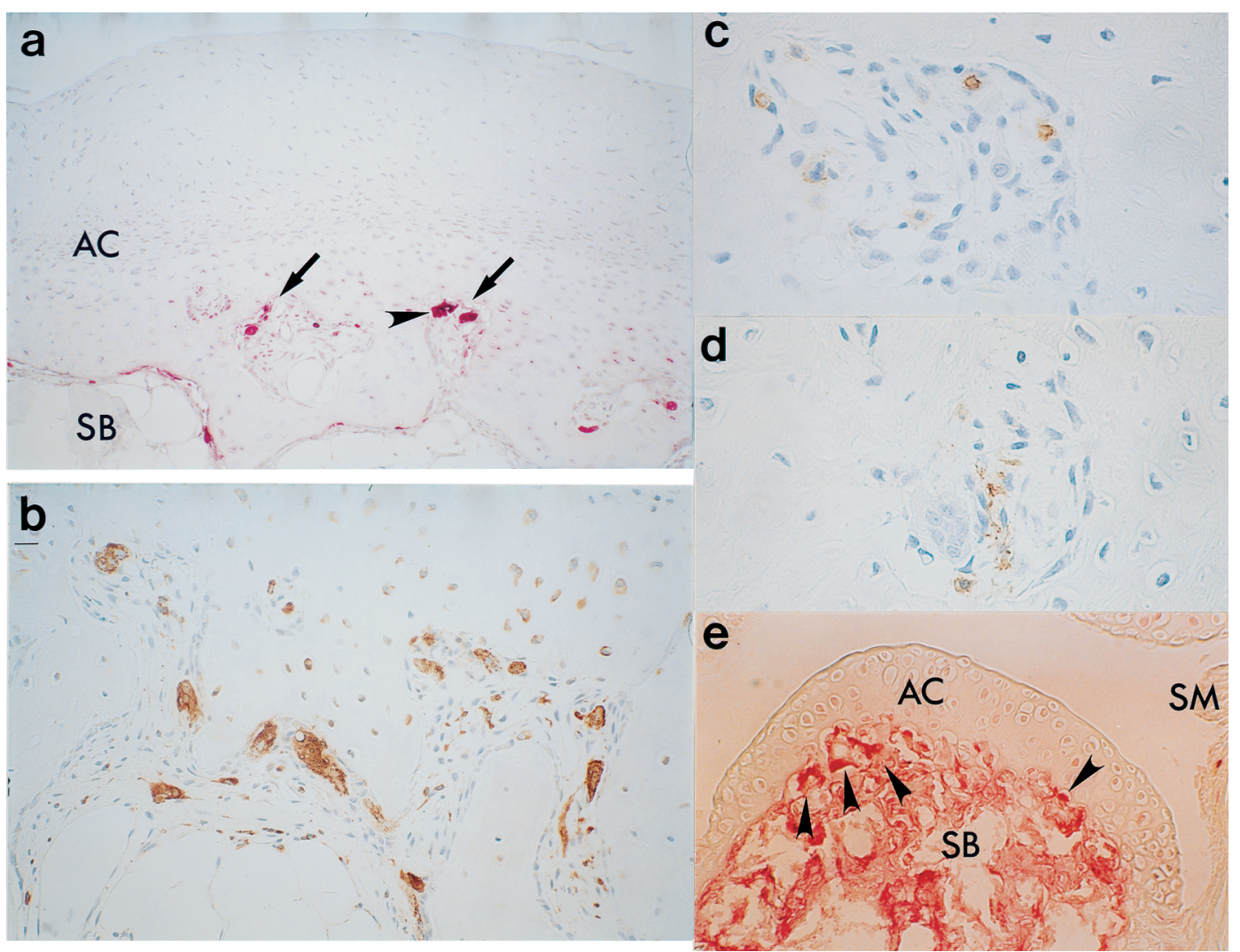

Figure 2 Immunostaining of sample tissues from RA patients ( $a-d)$ and $M R L / M p$-lprllpr mouse (e). The staining for TRAP was performed according to the method of Burstone. ${ }^{21}$ Immunostaining was done as described in figure 1, using mouse monoclonal antibody against human CD68 (Dako, Denmark), HLA-DR (Dako, Denmark), and leucocyte T cell (MT1, Bio-science products, Switzerland). (a) Islands (arrows) that invaded into the deep zone of articular cartilage (AC) through the calcified cartilage from the subchondral bone (SB). TRAP positive multinucleated cells (arrowhead); (b) CD68 positive cells; (c) MT-1 positive cells; (d) HLA-DR positive cells in islands and subchondral bone. (e) TRAP positive multinucleated cells (arrows) beneath undamaged AC preceding remarkable inflammation of the synovial membrane $(S M)$. ((a) Original magnification $\times 13.2$, (b) original magnification $\times 66,(c)$ to (e) original magnification $\times$ 132). 

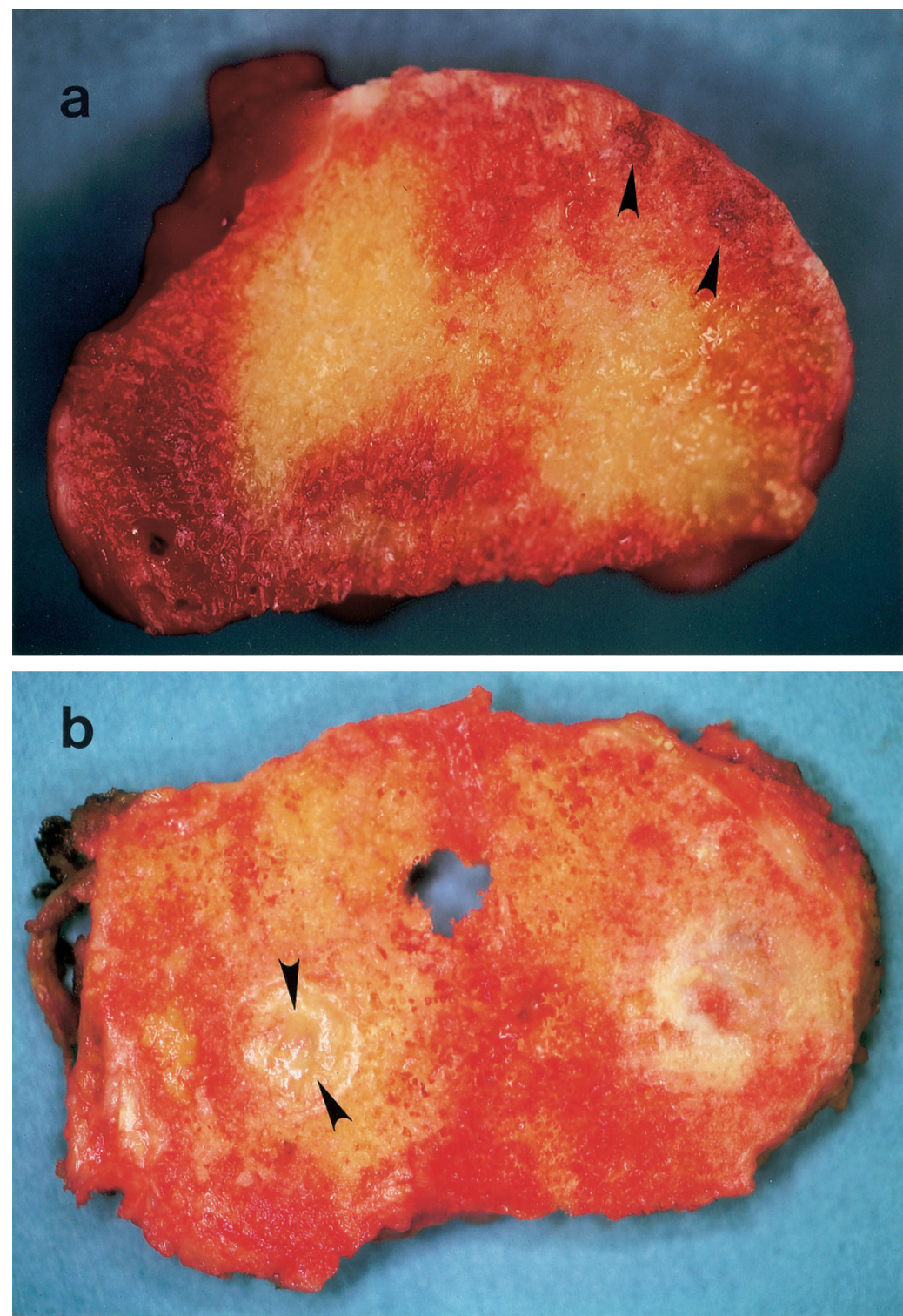

Figure 3 Macroscopical photograph of slices taken through the femoral head (a frontal section) and tibial plateau (a horizontal section) removed from 27 year old female and 56 year old female RA patients, respectively. (a) Small cystic areas are observed in the subchondral bone of the superior surface of a femoral head. (b) An area of cystic change in subchondral bone of medial tibial plateau. Such cysts $(a, b)$ are seen apart from bare area and in the existence of the overlying articular cartilage (b, cartilage is opposite side of the cyst in the photograph).
Thus, by continuously concentrating on the study of synovitis, the actual key event in the aetiology of RA may be overlooked. We propose the possibility that the initiation of the rheumatoid process is triggered by the autoimmune reaction involving type II collagen in the articular cartilage as a consequence of an unknown aetiological agent. Synovitis and other extra-articular features may be induced secondary to the immune complex formation in the subchondral area. In fact, a previous study showed that insoluble IgG antibodyantigen complexes are capable of initiating the release of inflammatory mediators from isolated macrophages in vivo. ${ }^{18}$ It seems possible that synovial inflammation, and all that accompanies it, may play a pivotal part in amplifying the earlier effects of an autoimmune reaction against type II collagen of articular cartilage. Presently, we do not possess the scientific evidence that excludes the possibility that very small changes in the synovial membrane are triggering the RA onset. However, we cannot exclude the possibility that osteoclast, macrophage and immunocyte infiltration as well as articular cartilage degradation are triggers. If the proposed sequence of events is proved, it will be ideal to direct our focus to medical treatment that suppress the invasion of osteoclastic cells and immunocytes in the subchondral bone rather than the inflammation of the synovial membrane.

1 Snowden N, Kay RA. Immunology of systemic rheumatoid disease. In: Saklatrala J, Walport MJ, eds. Immunology of rheumatoid disease. New York: Churchill Livingstone, 1995:437-48.

2 Firestein GS. Rheumatoid synovitis and pannus. In: Klippel JH, Dieppe PA, eds. Rheumatology. 2nd ed. London: Mosby, 1998:section 5 13.1-24

3 Flatt AE. Results of surgery. In: The care of the rheumatoid hand. 2nd ed. Saint Louis: Mosby, 1968:185-227.

4 Clayton ML. Synovectomy. In: Clayton ML, Smyth CJ, eds. Surgery for rheumatoid arthritis. New York: Churchill Livingstone, 1992:91-101

5 Fiocco U, Cozzi L, Rigon C, Chieco-Bianchi F, Baldovin M Cassisi GA, et al. Arthroscopic synovectomy in rheumatoid and psoriatic knee joint synovitis: Long-term outcome. Br J Rheumatol 1996;35:463-70.

6 Bullough PG. The inflammatory arthritides. In: Orthopedic pathology. 2nd ed. New York: Gower Medical, 1992:11.122 .

7 Laskin RS. Total condylar knee replacement in patients who have rheumatoid arthiritis. A ten-year follow-up study. J Bone Joint Surg 1990;72-A:529-35.

8 Ranawat CS, Rodriguez JA. The knee in rheumatoid arthritis. In: Baumgartner H, Dvorak J, Grob D, Munzinger U, Simmen BR, eds. Rheumatoid arthritis. Stuttgart: Georg Thieme Verlag, Thieme Medical, 1995:94-109.

9 Fujii K, Tsuji M, Murota K, Terato K, Shimozuru Y, Naga Y. An improved enzyme-linked immunosorbent assay of anti-collagen antibodies in human serum. J Immuno Methods 1990;124:63-70.

10 Terato K, Shimozuru Y, Katayama K, Takemitsu Y, Yamashita I, Miyatsu M, et al. Specificity of antibody to type II collagen in rheumatoid arthritis. Arthritis Rheum 1990;33: collagen in

11 Fujii K, Tsuji M, Kitamura A, Murota K. The diagnostic significance of anti-type II collagen antibody assay in rheusignificance of anti-type II collagen antibody
matoid arthritis. Int Orthop 1992;16:272-6.

12 Dodge GR, Poole AR. Immunohistochemical detection and immunochemical analysis of type II collagen degradation in human normal, rheumatoid and osteoarthritic articular cartilage cultured with interleukin 1. J Clin Invest 1989;83 647-61.

13 Trentham DE, Townes AS, Kang AH. Autoimmunity to type II collagen: an experimental model of arthritis. J Exp Med 1977;146:857-68.

14 Stuart JM, Dixon FJ. Serum transfer of collagen-induced arthritis in mice. J Exp Med 1983;158:378-92.

15 Seki N, Sudo Y, Yamane A, Sgihara S, Takai Y, Ishihara K, et al. Type II collagen-induced murine arthritis. II. Genetic et al. Type II collagen-induced murine arthritis. II. Genetic control of arthrits induction is expressed on L $3 \mathrm{~T}_{+} \mathrm{T}$ cells rquired for bumoral as well as cell-mediated immune
responses to type II collagen. Reg Immunol 1989;2:20312.

those in human subchondral bone with preceding remarkable inflammation of synovia membrane (fig 2). 
16 Koopman WJ, Gay S. The MRL-lpr/lpr mouse. A model for the study of rheumatoid arthritis. Scand J Rheumato 1988;75:284-9.

17 Tarkowski A, Holmdahl R, Rubin K, Klareskog L, Nisson LA, Gunnarsson K. Patterns of autoreactivity to collagen type II in autoimmune MRL/1 mice. Clin Exp Immunol 1986;63:441-9.

18 Riches DW, Stanworth DR. Evidence for a mechanism for the initiation of acid hydrolase secretion by macrophages complement activation. Biochem J 1982;202:639-45.
19 McLean IW, Nakane PK. Periodate-lysine-paraformal dehyde fixative. A new fixative for immunoelectron microscopy. J Histochem Cytochem 1974;22:1077-83.

$20 \mathrm{Hsu}$ S-M, Raine L, Fanger H. Use of avidin-biotinperoxidase complex (ABC) in immunoperoxidas techniques: A comparison between $\mathrm{ABC}$ and unlabeled antibody (PAP) procedures. J Histochem Cytochem 1981; 29:577-80.

21 Burstone MS. Histochemical demonstration of acid phosphatases with naphthol as-phosphates. J Natl Cancer Inst 1958;21:523-39. 